\title{
貨物自動車の積載荷重を測定する一方法について*
}

\author{
石 坂 昭 夫*1, 楢林 達 雄*1, 尾 崎晃一*2
}

\section{A Measurement Method of Carrying Load on a Truck}

\author{
Akio ISHIZAKA*3, Tatsuo NARABAYASHI and Kouichi OZAKI*2 \\ ${ }^{* 1}$ Precision Engineering, Tokai University,
}

1117 Kitakaname, Hiratsuka shi, Kanagawa, 259-1292 Japan

\begin{abstract}
The carrying load on a truck is usually measured by a truck scale or a portable measuring device of carring load. These are the method of measuring the sum of the weight of the truck itself and the carrying load. On the other hand it is also thinkable that the value of the carrying load is given by using the elastic deformation that the carrying load produces on a truck body. The proposed method here is one using the strains of front and rear axle induced by the load. In this paper it is proved that this method properly gives the value of the carrying load. If the above method would be realized and the value of load is visually indicated, it is greatly expected that this method effectively prevents carring the over load.
\end{abstract}

Key Words: Truck, Carrying load, Measurement

1. は じめに

货物自動車の積载重量はトラックスケールやポータ ブル車両重量測定装置によって測定される場合が多い. いずれも自功車と货物の合算重量を測定する方法であ る. これに対して, 樌載される前後の車体の変形の差 を利用して積載荷重を測定する方法が考えられる.

これまでに，車体のフレームの変形を利用した方法 も提案されたが，ここで提案する方法は積载したとき に生じる前車軸と後車軸の歪を検出することによって 樌載荷重を求める方法である．この方法によれば荷台 のどこに货物が貫かれても正しく重量を測定できる.

以下，この方法の有効性を货物自县車のモデルで定 量的に証明し，さらにこの結果をモデルと同じものを 製作して実験で確認した.

この提案が実用化されれば車の停止時に常に榡载重 量が表示することができ，過積载防止に大いなる効果 を発揮するものと期待できる.

本文では, はじめに, 後車軸のみ取り上げ荷重の軸 方向の位置の相違に関わらず車軸中央の歪が同じにな ることを示し (2 次元モデル), ついで, 前車軸と後者 軸の中央の歪を同時に取り出すこと (3 次元モデル)に よって積载荷重の大きさを測定することができること を示す. 2 次元モデルと異なり 3 次元モデルの解析の

* 原稿受付 2004 年 9 月 1011 .

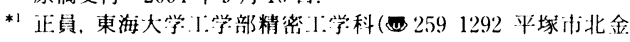
H1117).

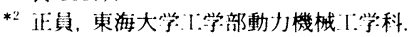

E mail : ishizaka (a keyaki.cc.u tokai.ac.jp
際には軸の撓みを考虑する必要がある。したがって， 解析は 2 次元モデルに比べ煩雑になるができるだけ単 純なモデルを用いて検討する.

\section{2. 解}

析

2.12 次元モデル货物自動車の後車軸の中心 軸を含む垂直な面で切った断面の模式図を図 1(a)に示 す.これを図 1(b)に示すように, フレームを剛体と仮 定し，㦟架装置である板ばねをコイルばね状に描き， 車軸および車軸管を含めた部分を弾性軸でモデル化し， 解析する. このモデルをここでは 2 次元モデルとよぶ.

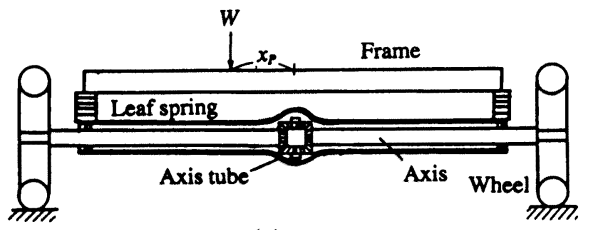

(a)

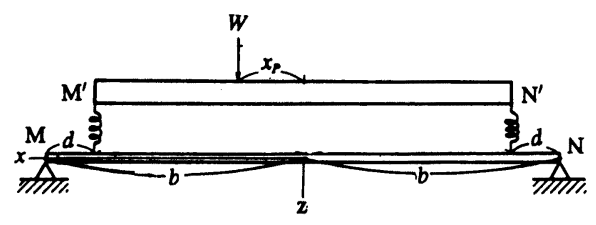

(b) 
フレームの $x=x_{P}$ の位置に集中荷重 $W$ が作用する 場合 (図 1(b) 参照), 軸 $M N$ の右端 $\mathrm{N}$ が車輪から受け る荷重 $r_{L}$ および板ばねを介して $\mathrm{N}^{\prime}$ から軸 $M N$ に与え られる力 $f_{L}$ は, フレームおよび軸を剛体としたとき の力の釣合条件から

$$
r_{L}=\frac{b-x_{P}}{2 b} W, \quad f_{L}=\frac{b-d-x_{P}}{2(b-d)} W
$$

と得られる. 軸 $M N$ の $-(b-d)<x<b-d$ の範囲で $x=x$ に作用する曲げモーメント $M$ は

$$
M=r_{L}(b+x)-f_{L}(b-d+x)
$$

で与えられるから，この式に式 (1) を代入することに よって

$$
M=\frac{\left(b^{2}-b d+x_{P} x\right) d}{2(b-d) b} W
$$

を得る. 車軸中央, すなわち $x=0$ に作用する曲げモ一 メントは上式から $W d / 2$ であり, 荷重の位置 $x_{P}$ に無 関倸になることがわかる.こういった関係が前後輪を 含めた 3 次元モデルに拡張した場合についも成立する ことを次節で証明する.

2.23 次元モデル モデル化する貨物自動車を図 2 に示す.この自動車を図 3(a) のようにモデル化する. 荷台のモデルである矩形板 $A B C D$ は質量零の剛体で, $\overline{A I}, \overline{B J}, \overline{D K}$ および $\bar{L}$ のばねを介してそれぞれ弾性軸 $\overline{E F}, \overline{G H}$ で支えられる.

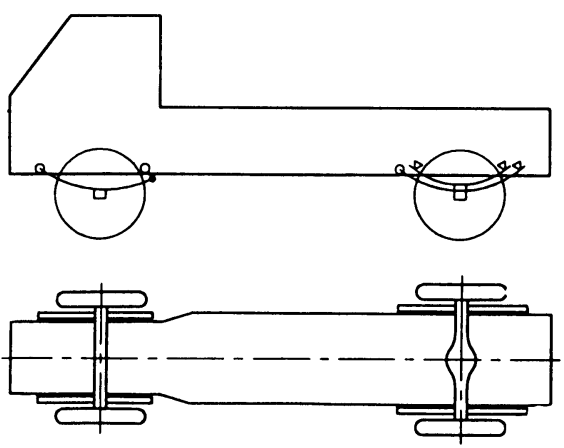

Fig.2 Truck to model

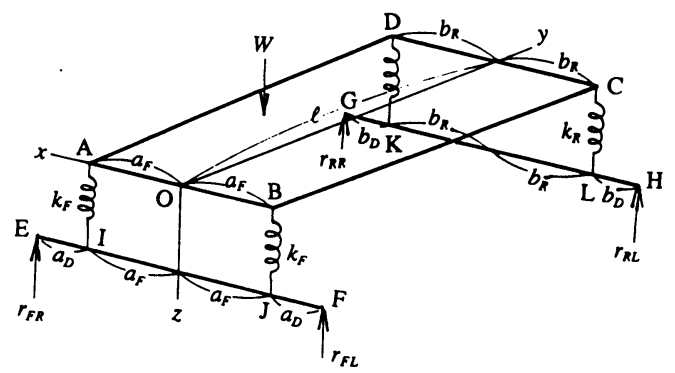

(a)

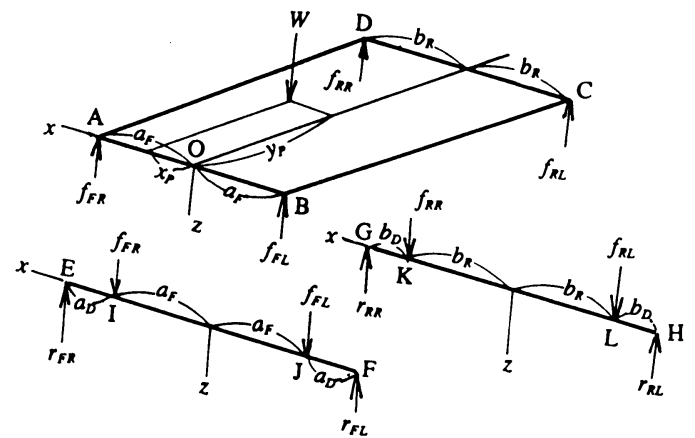

(b)

Fig.3 Analytical model of the truck

図 3(b) に荷台および前車軸と後車軸の自由物体図 を示す. 荷台には $x=x_{P}, y=y_{P}$ の位膡に集中荷重 $W$

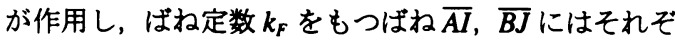

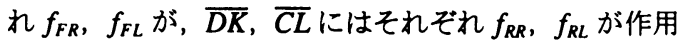
する. 荷台の $z$ 方向の力と $x$ 軸周りと $y$ 軸周りのモ一 メントの釣り合い条件から，荷台について

$$
\begin{aligned}
f_{F R}+f_{F L}+f_{R R}+f_{R L} & =W, \\
W y_{P}-\left(f_{R L}+f_{R R}\right) \ell & =0, \\
-W x_{P}+f_{F R} a_{F}+f_{R R} b_{R}-f_{F L} a_{F}-f_{R L} b_{R} & =0
\end{aligned}
$$

が成立する.ここで， $\ell, a_{F}, b_{R}$ は図 3(a) に示す寸法で ある. 荷台の変位を図 (b) のO点の垂下量 $z$ と， $x$ 軸 周りおよび $y$ 軸周りの角変位 $\theta_{x}$ と $\theta_{y}$ で表し，ばねの 力を受ける軸の $\mathrm{I}, \mathrm{J}, \mathrm{K}$ および $\mathrm{L}$ 点の変位をそれぞれ

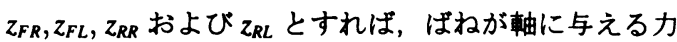
は次式で与えられる.

$$
\begin{aligned}
f_{F R} & =k_{F}\left(z-a_{F} \theta_{y}-z_{F R}\right), \\
f_{F L} & =k_{F}\left(z+a_{F} \theta_{y}-z_{F L}\right), \\
f_{R R} & =k_{R}\left(z+\ell \theta_{x}-b_{R}-\theta_{y}-z_{R R}\right), \\
f_{R L} & =k_{R}\left(z+\ell \theta_{x}+b_{R}-\theta_{y}-z_{R L}\right) .
\end{aligned}
$$

前車軸と後車軸の剛体としての验合条件はタイヤを介 して路面から受ける力を図示のように $r_{F R}, r_{F L}, r_{R R} お$ よび $r_{R L}$ とすれば

$$
\begin{aligned}
r_{F R}+r_{F L}-f_{F R}-f_{F L} & =0, \\
r_{R R}+r_{R L}-f_{R R}-f_{R L} & =0, \\
f_{F L} a_{F}-f_{F R} a_{F}+r_{F R} a-r_{F L} a & =0, \\
f_{R L} b_{R}-f_{R R} b_{R}+r_{R R} b-r_{R L} b & =0 .
\end{aligned}
$$

ただし $, a=a_{F}+a_{D}, \quad b=b_{R}+b_{D}$ と置いた 
一方, 前車軸の撓みを下゙式で示すように $x$ の範囲 によって $z_{F 1}, z_{F 2}, z_{F 3}$ と置き， $x$ に関する微分をダッ シュ記号で示し, 前車軸の曲げ剛性を $B_{F}$ とすれば

$$
\begin{aligned}
a_{F}<x<a:-B_{F} z_{F 1}^{\prime \prime} & =r_{F R}(a-x), \\
-a_{F}<x<a_{F}:-B_{F} z_{F 2}^{\prime \prime} & =r_{F R}(a-x)-f_{F R}\left(a_{F}-x\right), \\
-a<x<-a_{F}:-B_{F} z_{F 3}^{\prime \prime} & =r_{F L}(a+x) .
\end{aligned}
$$

上式を $x$ で 1 回, 2 回と積分すると, 次式が与えられる.

$$
\begin{aligned}
& -B_{F} z_{F 1}^{\prime}=r_{F R}\left(a x-\frac{x^{2}}{2}\right)+C_{11}, \\
& -B_{F} z_{F 2}^{\prime}=r_{F R}\left(a x-\frac{x^{2}}{2}\right)-f_{F R}\left(a_{F} x-\frac{x^{2}}{2}\right)+C_{21} \\
& -B_{F} z_{F 3}^{\prime}=r_{F L}\left(a x+\frac{x^{2}}{2}\right)+C_{31} \\
& -B_{F} z_{F 1}=r_{F R}\left(\frac{a}{2} x^{2}-\frac{x^{3}}{6}\right)+C_{11} x+C_{12}, \\
& -B_{F} z_{F 2}=r_{F R}\left(\frac{a}{2} x^{2}-\frac{x^{3}}{6}\right)-f_{F R}\left(\frac{a_{F}}{2} x^{2}-\frac{x^{3}}{6}\right) \\
& -B_{F} z_{F 3}=r_{F L}\left(\frac{a}{2} x^{2}+\frac{x^{3}}{6}\right)+C_{31} x+C_{32} .
\end{aligned}
$$

上式に含まれる 6 個の積分定数 $C_{11}, C_{21}, C_{31}, C_{12}, C_{22}$, $C_{32}$ は次の 6 個の境界条件

$$
\begin{gathered}
\left.z_{F 3}\right|_{x=-a}=\left.z_{F 1}\right|_{x=a}=0, \\
\left.z_{F 3}\right|_{x=-a_{F}}=\left.z_{F 2}\right|_{x=-a_{F}},\left.z_{F 2}\right|_{x=a_{F}}=\left.z_{F 1}\right|_{x=a_{F}}, \\
\left.z_{F 3}^{\prime}\right|_{x=-a_{F}}=\left.z_{F 2}^{\prime}\right|_{x=-a_{F}},\left.z_{F 2}^{\prime}\right|_{x=a_{F}}=\left.z_{F 1}^{\prime}\right|_{x=a_{F}}
\end{gathered}
$$

に式(6) を代入して得られる $C_{11}, C_{21}, C_{31}, C_{12}, C_{22}$ および $C_{32}$ に関する連立方程式から次のように求めら れる.

$$
\begin{gathered}
C_{11}=-\frac{\left(3 a-a_{F}\right) a_{F}^{2}}{3 a} f_{F R}+\frac{a_{D}^{3}}{6 a} r_{F L} \\
-\frac{a^{3}-3 a^{2} a_{F}+a_{F}^{3}}{6 a} r_{F R}, \\
\begin{aligned}
C_{12}=-\frac{\left(3 a-a_{F}\right) a_{F}^{2}}{3} f_{F R}- & \frac{a_{D}^{3}}{6} r_{F L} \\
& -\frac{a^{3}+3 a^{2} a_{F}-a_{F}^{3}}{6} r_{F R}, \\
C_{21}=-\frac{\left(3 a-2 a_{F}\right) a_{F}^{2}}{6 a} f_{F R}+\frac{a_{D}^{3}}{6 a} r_{F L} & -\frac{a^{3}-3 a^{2} a_{F}+a_{F}^{3}}{6 a} r_{F R}, \\
C_{22}=-\frac{\left(2 a-a_{F}\right) a_{F}^{2}}{2} f_{F R}- & \frac{a_{D}^{3}}{6} r_{F L} \\
& -\frac{a^{3}+3 a^{2} a_{F}-a_{F}^{3}}{6} r_{F R}, \\
C_{31}=-\frac{\left(3 a+a_{F}\right) a_{F}^{2}}{3 a} f_{F R}+\frac{a^{3}+3 a^{2} a_{F}-a_{F}^{3}}{6 a} r_{F L} & -\frac{\left(a+a_{F}\right)^{3}}{6 a} r_{F R},
\end{aligned}
\end{gathered}
$$

$$
\begin{gathered}
C_{32}=-\frac{\left(3 a+a_{F}\right) a_{F}^{2}}{3} f_{F R}-\frac{a^{3}-3 a^{2} a_{F}-a_{F}^{3}}{6} r_{F L} \\
-\frac{\left(a+a_{F}\right)^{3}}{6} r_{F R} .
\end{gathered}
$$

ここで, $z_{F R}$ およひ $z_{F L}$ は, 次式

$$
z_{F R}=\left.z_{1 F}\right|_{x=a_{F}}, \quad z_{F L}=\left.z_{3 F}\right|_{x=-a_{F}}
$$

であるから，式(7) の $C_{11}, C_{31}, C_{12}, C_{32}$ を代入した式 (6) を上式に代入すれば $z_{1 F}$ と $z_{3 F}$

$$
\begin{aligned}
& z_{F R}=\frac{a_{D}}{6 a B_{F}}\left\{-2\left(3 a-a_{F}\right) a_{F}^{2} f_{F R}+a_{D}^{3} r_{F L}\right. \\
& \left.+\left(a^{3}+5 a^{2} a_{F}-a a_{F}^{2}-a_{F}^{3}\right) r_{F R}\right\}, \\
& z_{F L}=\frac{a_{D}}{6 a B_{F}}\left\{-2\left(3 a+a_{F}\right) a_{F}^{2} f_{F R}+a_{D}^{3}\left(a+a_{F}\right) r_{F L}\right. \\
& \left.+\left(a+a_{F}\right)^{3} r_{F R}\right\}
\end{aligned}
$$

と求めることができる.

後車軸のばね力を受ける点 $\mathrm{K}, \mathrm{L}$ での撓み $z_{R R}$ およ び $z_{R L}$ も, 前車軸の曲げ剛性を $B_{R}$ とすれば

$$
\begin{gathered}
z_{R R}=\frac{b_{D}}{6 b B_{R}}\left\{-2\left(3 b-b_{R}\right) b_{R}^{2} f_{R R}+b_{D}^{3} r_{R L}\right. \\
\left.+\left(b^{3}+5 b^{2} b_{R}-b b_{R}^{2}-b_{R}^{3}\right) r_{R R}\right\}, \\
z_{R L}=\frac{b_{D}}{6 b B_{R}}\left\{-2\left(3 b+b_{R}\right) b_{R}^{2} f_{R R}+b_{D}^{3}\left(b+b_{R}\right) r_{R L}\right\} \\
\left.+\left(b+b_{R}\right)^{3} r_{R R}\right\}
\end{gathered}
$$

と得られる.これらの值 $z_{F R}, z_{F L}, z_{R R}, z_{R L}$ を式(4)に 代入した式と式 (3),(5) の式は 11 個の未知量 $f_{F R}, f_{F L}$, $f_{R R}, f_{R L}, r_{F R}, r_{F L}, r_{R R}, r_{R L}, \theta_{x}, \theta_{y}, z$ に関する 11 元 連立方程式

$$
\begin{gathered}
\frac{3 a B_{F}-a_{D}\left(3 a-a_{F}\right) a_{F}^{2} k_{F}}{3 a B_{F}} f_{F R}+\frac{a_{D}^{4} k_{F}}{6 a B_{F}} r_{F L}-k_{F} z \\
+\frac{a_{D}\left(a^{3}+5 a^{2} a_{F}-a a_{F}^{2}-a_{F}^{3}\right) k_{F}}{6 a B_{F}} r_{F R}+a_{F} k_{F} \theta_{y}=0, \\
f_{F L}-\frac{a_{D} a_{F}^{2}\left(3 a+a_{F}\right) k_{F}}{3 a B_{F}} r_{F R}+\frac{a_{D}^{3}\left(a+a_{F}\right) k_{F}}{6 a B_{F}} r_{F L}-k_{F} z \\
+\frac{a_{D}\left(a+a_{F}\right)^{3} k_{F}}{6 a B_{F}} r_{F R}-a_{F} k_{F} \theta_{y}=0, \\
+\frac{b_{D}\left(b^{3}+5 b^{2} b_{R}-b b_{R}^{2}-b_{R}^{3}\right) k_{R}}{6 b B_{R}} r_{R R}-k_{R} \ell \theta_{x}+b_{R} k_{R} \theta_{y}=0, \\
f_{R L}-\frac{b_{D} b_{R}^{2}\left(3 b+b_{R}\right) k_{R}}{3 b B_{R}} r_{R R}+\frac{b_{D}^{3}\left(b+b_{R}\right) k_{R}}{6 b B_{R}} r_{R L}-k_{R} z \\
+\frac{b_{D}\left(b+b_{F}\right)^{3} k_{R}}{6 b B_{R}} r_{R R}-k_{R} \ell \theta_{x}-b_{R} k_{R} \theta_{y}=0, \\
f_{F R}+f_{F L}+f_{R R}+f_{R L}=W, \ell f_{R L}+\ell f_{R R}-W y_{P}=0, \\
a_{F} f_{F R}+b_{R} f_{R R}-a_{F} f_{F L}-b_{R} f_{R L}-W x_{P}=0, \\
r_{F R}+r_{F L}-f_{F R}-f_{F L}=0, r_{R R}+r_{R L}-f_{R R}-f_{R L}=0, \\
a_{F} f_{F L}-a_{F} f_{F R}+a r_{F R}-a r_{F L}=0, \\
b_{R} f_{R L}-b_{R} f_{R R}+b r_{R R}-b r_{R R}=0
\end{gathered}
$$


を与える.この方程式を解くと，

$$
\theta_{x}=\frac{N_{x}}{6 D_{x}} W, \theta_{y}=\frac{N_{y}}{6 D_{y}} W, z=\frac{N_{z}}{6 D_{z}} W .
$$

ここで,

$N_{x}=-a_{D}^{2}\left(a+2 a_{F}\right) k_{F} k_{R} y_{L} B_{R}+b_{D}^{2}\left(b+2 b_{R}\right) k_{F} k_{R} y_{P} B_{F}$

$$
-3\left(k_{R} y_{L}-k_{F} y_{P}\right) \text {, }
$$

$N_{y}=-\left(3 a B_{F}+a_{D}^{2} a_{F}^{2} k_{F}\right)\left(3 b B_{R}+b_{D}^{2} b_{R}^{2} k_{R}\right) x_{P}$,

$N_{z}=3 B_{F}+a_{D}^{2}\left(a+2 a_{F}\right) k_{F}, D_{x}=6 \ell^{2} k_{F} k_{R} B_{F} B_{R}$,

$D_{y}=3 a b\left(a_{F}^{2} k_{F}+b_{R}^{2} k_{R}\right) B_{F} B_{R}+a_{D}^{2} b b_{R}^{2} k_{F} k_{R} B_{R}+a a_{F}^{2} b_{R}^{2} k_{F} k R$,

$D_{z}=6 B_{F} k_{F} \ell$.

さらに,

$$
\begin{aligned}
f_{F R} & =\frac{N_{f_{F R}}}{D} \frac{W \ell}{2}, f_{F L}=\frac{N_{f_{F L}}}{D} \frac{W \ell}{2}, f_{R R}=\frac{N_{f_{R R}}}{D} \frac{W \ell}{2}, \\
f_{R L} & =\frac{N_{f_{R L}}}{D} \frac{W \ell}{2}, r_{F R}=\frac{N_{r_{F R}}}{D} \frac{W \ell}{2}, r_{F L}=\frac{N_{r_{F L}}}{D} \frac{W \ell}{2}, \\
r_{R R} & =\frac{N_{r_{R R}}}{D} \frac{W \ell}{2}, r_{R L}=\frac{N_{r_{R L}}}{D} \frac{W \ell}{2}
\end{aligned}
$$

である.ここで,

$$
\begin{aligned}
& N_{f_{F R}}=3 a b B_{F} B_{R}\left(a_{F} k_{F} l x_{P}+a_{F}^{2} k_{F} y_{L}+b_{R}^{2} k_{R} y_{L}\right) \\
& +a b a_{F}^{2} a_{D}^{2} b_{R}^{2} k_{F} k_{R} B_{R} y_{L} \\
& +a B_{F} a_{F} b_{D}^{2} b_{R}^{2} k_{F} k_{R}\left(-\ell x_{P}+a_{F} y_{L}\right) \text {, } \\
& N_{f_{F L}}=3 a b B_{F} B_{R}\left(-a_{F} k_{F} l x_{P}+a_{F}^{2} k_{F} y_{L}+b_{R}^{2} k_{R} y_{L}\right) \\
& +a b a_{F}^{2} a_{D}^{2} b_{R}^{2} k_{F} k_{R} B_{R} y_{L} \\
& +a B_{F} a_{F} b_{D}^{2} b_{R}^{2} k_{F} k_{R}\left(l x_{P}+a_{F} y_{L}\right) \text {, } \\
& N_{f_{R R}}=3 a b B_{F} B_{R}\left(b_{R} k_{R} l x_{P}+a_{F}^{2} k_{F} y_{P}+b_{R}^{2} k_{R} y_{P}\right) \\
& +b a_{F}^{2} a_{D}^{2} b B_{R} k_{F} k_{R}\left(l x_{P}+b_{R} y_{P}\right)+a b B_{F} a_{F}^{2} b_{D}^{2} b_{R}^{2} k_{F} k_{R} \text {, } \\
& N_{f_{R L}}=3 a b B_{F} B_{R}\left(-b_{R} k_{R} \ell x_{P}+a_{F}^{2} k_{F} y_{P}+b_{R}^{2} k_{R} y_{P}\right) \\
& +b a_{F}^{2} a_{D}^{2} b B_{R} k_{F} k_{R}\left(-\ell x_{P}+b_{R} y_{P}\right)+a b B_{F} a_{F}^{2} b_{D}^{2} b_{R}^{2} k_{F} k_{R} \text {, } \\
& N_{r_{F R}}=3 b B_{F} B_{R}\left\{\dot{a}_{F}^{2} k_{F} l x_{P}+a\left(a_{F}^{2} k_{F}+b_{R}^{2} k_{R}\right) y_{L}\right\} \\
& +b a_{F}^{2} a_{D}^{2} b B_{R} k_{F} k_{R}\left(\ell-y_{P}\right) \\
& +B_{F} a_{F}^{2} b_{D}^{2} b_{R}^{2} k_{F} k_{R}\left\{l x_{P}+a y_{L}\right\} \text {, } \\
& N_{r_{F L}}=3 b B_{F} B_{R}\left\{-a_{F}^{2} k_{F} l x_{P}+a\left(a_{F}^{2} k_{F}+b_{R}^{2} k_{R}\right) y_{L}\right\} \\
& +b a_{F}^{2} a_{D}^{2} b B_{R} k_{F} k_{R}\left(\ell-y_{P}\right) \\
& -B_{F} a_{F}^{2} b_{D}^{2} b_{R}^{2} k_{F} k_{R}\left\{l x_{P}-a\left(\ell+y_{P}\right)\right\} \text {, } \\
& N_{r_{R R}}=3 a B_{F} B_{R}\left\{b a_{F}^{2} k_{F} y_{P}+b_{R}^{2} k_{R}\left(-\ell x_{P}+b y_{P}\right)\right\} \\
& +B_{R} a_{D}^{2} a_{F}^{2} b_{R}^{2} k_{F} k_{R}\left(\ell x_{P}+b_{R} y_{P}\right)+a b B_{F} a_{F}^{2} b_{D}^{2} b_{R}^{2} k_{F} k_{R} y_{P}, \\
& N_{r_{R L}}=3 a B_{F} B_{R}\left\{b a_{F}^{2} k_{F} y_{P}+b_{R}^{2} k_{R}\left(-\ell x_{P}+b y_{P}\right)\right\} \\
& -B_{R} a_{D}^{2} a_{F}^{2} b_{R}^{2} k_{F} k_{R}\left(l x_{P}-b_{R} y_{P}\right)+a b B_{F} a_{F}^{2} b_{D}^{2} b_{R}^{2} k_{F} k_{R} y_{P}, \\
& D=3 a b B_{F} B_{R}\left(a_{F}^{2} k_{F}+b_{R}^{2} k_{R}\right) \\
& +b B_{R} a_{D}^{2} a_{F}^{2} k_{F} k_{R}+a B_{F} a_{F}^{2} b_{D}^{2} b_{R}^{2} k_{F} k_{R}
\end{aligned}
$$

である。 また，上式で $y_{L}$ は $\ell-y_{P}$ である.

前車軸中央と後者軸中央のモーメントをそれぞれ $M_{F}, M_{R}$ とすると

$$
M_{F}=r_{F R} a-f_{F R} a_{F}, \quad M_{R}=r_{R R} b-f_{R R} b_{R}
$$

であるから，上式に式 (8) を代入して整理すると，

$$
M_{F}=\frac{a_{D} W}{2} \frac{\ell-y_{P}}{\ell}, \quad M_{R}=\frac{b_{D} W}{2} \frac{y_{P}}{\ell} .
$$

と簡単な式を得る。したがって，前車軸中央と後者軸 中央の歪をそれぞれ $\varepsilon_{F}$ と $\varepsilon_{R}$ とすれば， $\varepsilon_{F} ， \varepsilon_{R}$ は

$$
\varepsilon_{F}=\frac{W}{\eta_{F}} \frac{\ell-y_{P}}{\ell}, \quad \varepsilon_{R}=\frac{W}{\eta_{R}} \frac{y_{P}}{\ell}
$$

で示される.ここで

$$
\eta_{F}=\frac{2 E_{F} Z_{F}}{a_{D}}, \quad \eta_{R}=\frac{2 E_{R} Z_{R}}{b_{D}}
$$

と置いた．また， $E_{F}$ と $E_{R}$ および $Z_{F}$ と $Z_{R}$ はそれぞれ 前車軸と後車軸のヤング率および断面係数である. 次の量 $Q$

$$
Q=\eta_{F} \varepsilon_{F}+\eta_{R} \varepsilon_{R}
$$

に式(9) の $\varepsilon_{F}$ と $\varepsilon_{R}$ を代入すると， $Q=W$ となる. し たがって， $Q$ を測定することによって積载量 $W$ を求 めることができる.

上式の $\varepsilon_{F}$ と $\varepsilon_{R}$ は歪み測定によって，また， $\eta_{F}$ お よび $\eta_{F}$ は式 (9) を用いて，予め測定しておくことが できる.

ここまで, 積載荷重が 1 個の場合について論じたが， 積載荷重 $\boldsymbol{W}$ を $\boldsymbol{n}$ 個の荷重に分割して荷台の任意の場 所に置いた場合についても，上記の值 $Q$ が積载重量 $W$ と一致することを証明することができる，すなわ ち, 分割された 1 つの荷重 $W_{i}(n=1,2, \ldots, n)$ が荷台 の $\left(x_{P_{i}}, y_{P_{i}}\right)$ の位置に掛けられたとすると, 前後軸の歪 $\varepsilon_{F i}, \varepsilon_{R i}$ は式 (9) から

$$
\varepsilon_{F i}=\frac{W_{i}}{\eta_{F}} \frac{\ell-y_{P i}}{\ell}, \quad \varepsilon_{R i}=\frac{W_{i}}{\eta_{R}} \frac{y_{P i}}{\ell} .
$$

本モデルは線形系を仮定しているので， $n$ 個の分割さ れた荷重による前車軸と後車軸のそれぞれの歪 $\varepsilon_{F}, \varepsilon_{R}$ は

$$
\varepsilon_{F}=\sum_{i=1}^{n} \varepsilon_{F i}, \quad \varepsilon_{R}=\sum_{i=1}^{n} \varepsilon_{R i}
$$

で与えられる．上式を式(10)に代入した式に，式(11) を代入してすると，次のように演算

$$
\begin{aligned}
Q & =\eta_{F} \sum_{i=1}^{n} \varepsilon_{F i}+\eta_{R} \sum_{i=1}^{n} \varepsilon_{R i} \\
& =\frac{1}{\ell} \sum_{i=1}^{n} W_{i}\left(\ell-y_{P i}\right)+\frac{1}{\ell} \sum_{i=1}^{n} W_{i} y_{P i} \\
& =\sum_{i=1}^{n} W_{i}=W
\end{aligned}
$$


ができて， $Q=W$ が証明される.

以上の解析から, 前車軸と後車軸の中央の歪から積 載された貨物が荷台のどの位置に置かれても，また， どのように分割されて置かれても積載重量の值を測定 できることを明らかにすることができた。

\section{3. 実験および結果}

図 3(a) に示す解析モデルと等価な模型を作製し，解 析から導いた式の検証を行う。図 4(a) に模型の図面お よび図 4(b) にその全景の写真を示す，荷台は縦横 20

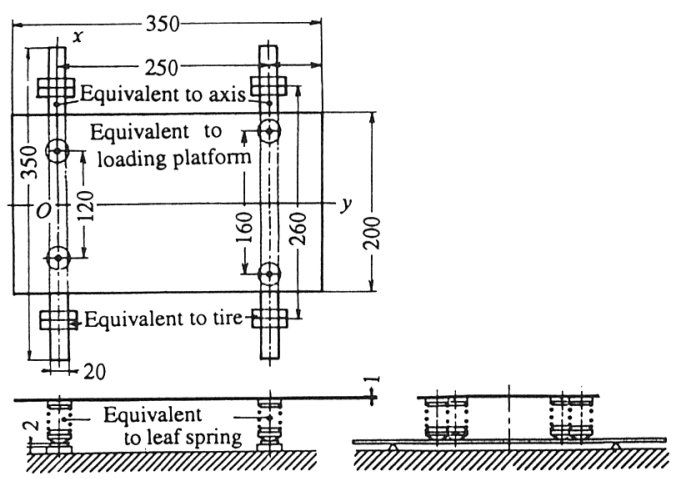

(a)

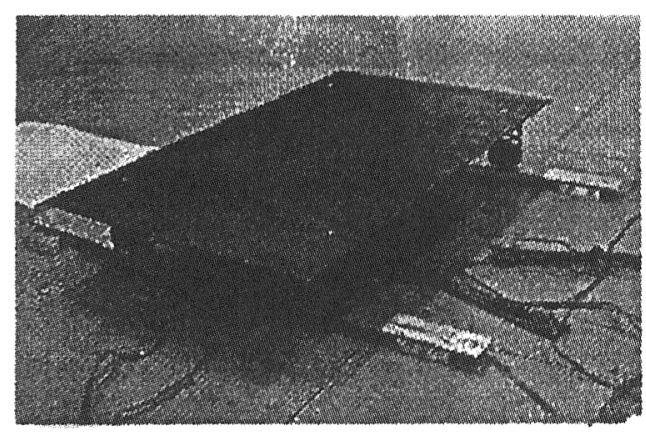

(b)

Fig.4 Experimental setup

$[\mathrm{cm}] \times 35[\mathrm{~cm}]$, 厚さ $1[\mathrm{~mm}]$ の泠間圧延鋼板で, 4 個の コイルばねで支持される.それらのばねは幅 26.5[mm], 厚さ $2.8[\mathrm{~mm}]$, 長さ $35[\mathrm{~cm}]$ の前車軸と後車軸に見立 てた短冊状の板で受け，その板はタイヤに見立てた 4 つのエッジを持つブロックで支えられている，荷台に は荷重を掛ける位置 $\left(x_{P}, y_{P}\right)$ を示すための $x-y$ 座標が 書き込まれている，また，前車軸と後車軸の中央には それぞれの歪量 $\varepsilon_{F}$ と $\varepsilon_{R}$ の検出をするために歪ゲージ が貼られている.

まず, 式 (9) は荷重 $W$ の作用点の $x$ 座標の值 $x_{P}$ に無
関係に， $\varepsilon_{F}$ および $\varepsilon_{R}$ が一定になることを示している. 図 5(a)〜 (d) に $y_{P}$ を固定して， $x_{P}$ を変えたときの $\varepsilon_{F}$ および $\varepsilon_{R}$ の変化を種々の $W$ の值に対して採った測定 結果を。で示す. 図の実線は各 $W$ の大きさ毎の $\varepsilon_{F}$ (図 (a)(b)) および $\varepsilon_{R}$ (図 (c)(d)) の平均值である。 $\varepsilon_{F}$ および $\varepsilon_{R}$ は $x_{P}$ に無関係に一定であることがわかる.

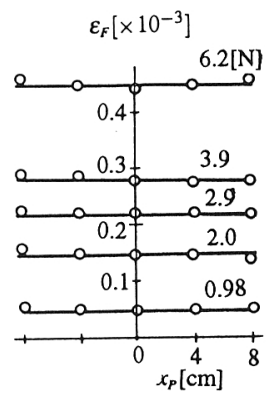

(a) $y_{P}=-1[\mathrm{~cm}]$

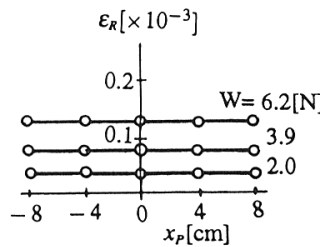

(c) $y_{P}=8[\mathrm{~cm}]$

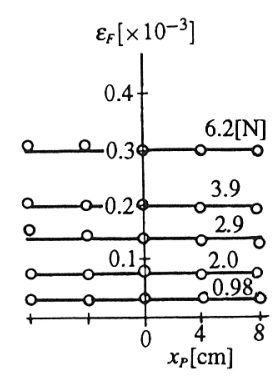

(b) $y_{P}=18[\mathrm{~cm}]$ $\varepsilon_{R}\left[\times 10^{-3}\right]$

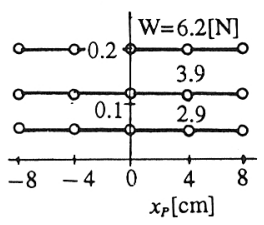

(d) $y_{P}=17[\mathrm{~cm}]$
Fig.5 Strain of a front axile $\varepsilon_{F}$ and a rear axile $\varepsilon_{R}$ to the load position $\left(x_{P}, y_{P}\right)$ when changing the load $W$

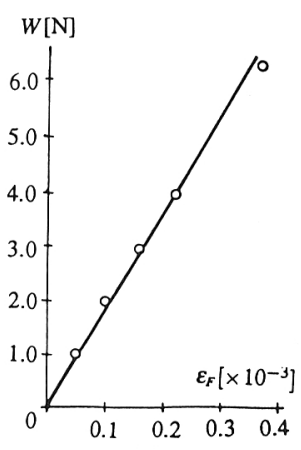

(a)

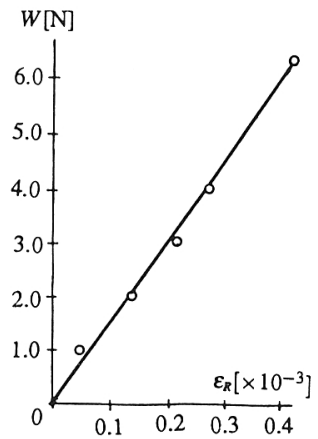

(b)
Fig.6 $\varepsilon_{F}$ and $\varepsilon_{R}$ to the $W$

さらに, 式 (9) の $y_{P}$ と $\varepsilon_{F}, \varepsilon_{R}$ の関係を確かめる. そ のためにまず式 (9) に含まれる $\eta_{F}$ と $\eta_{R}$ を求めるため の実験を行った。 その結果を図 6 に示す. 図 (a) には $x_{P}=0, y_{P}=0$ としたときの $W$ と $\varepsilon_{F}$ の関係を, 図 (b) に は $x_{P}=0, y_{P}=25[\mathrm{~cm}]$ としたときの $\varepsilon_{R}$ とW の測定結果 
を示す. 式(9)から図 (a) および (b) の直線の勾配がそ れぞれ $\eta_{F}$ と $\eta_{R}$ を与えることがわかる. その結果は

$$
\eta_{F}=14.32 \times 10^{3}[\mathrm{~N}], \quad \eta_{R}=33.6 \times 10^{3}[\mathrm{~N}]
$$

であった．式(9) から図 6 の場合のようにWを必ずし も車軸の真上に直かなくても $\varepsilon_{F}$ と $\varepsilon_{R}$ を求めることが できることは明らかである. 図 7 は， $\varepsilon_{F}$ と $\varepsilon_{R}$ を $y_{P}$ に 対して積載荷重 $W$ 別に実験值 ( $x_{P}=0$ の場合) をプロッ トした図である. 図には式 (13) の值を式 (9)に代入し た式が表す直線も書き込まれている. 実鈋值がよく直 線に载っていることがわかる.

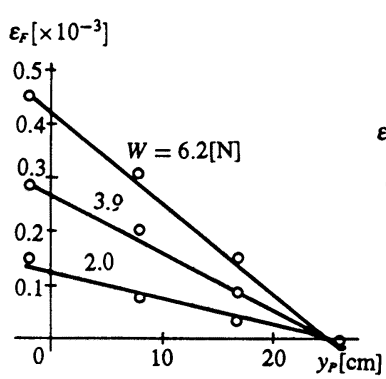

(a)

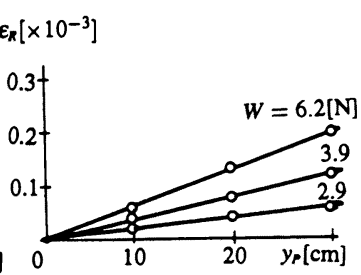

(b)
Fig.7 $\varepsilon_{F}$ and $\varepsilon_{R}$ to the $y_{P}$ when changing $W$

つぎに, $x_{P}=0$ の場合の実験結果を用いて式 (10) を 確認する. 式中の $\eta_{F}$ と $\eta_{R}$ には式 (13) の值, そして, 測定結果の $\varepsilon_{F}$ および $\varepsilon_{R}$ を用いて式 (10)の右辺を計算 した結果をプロットした図に, $Q=W$ の実線を書き込 んだものを図 9 に示す. 実線から少し離れた測定結果 が 1 部あるが, 式 (10)の正しいことがわかる.

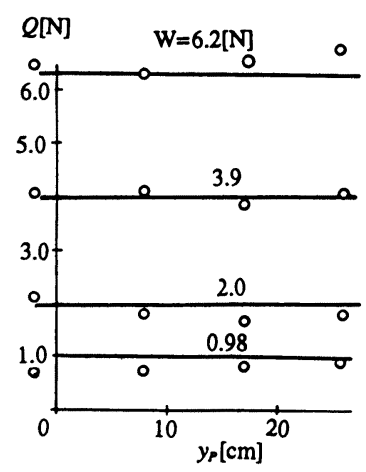

Fig.8 Value of eq.(10) $Q$ to the $y_{P}$ when changing $W$

最後に，荷台に積载された一定の荷重が分割されて 置かれても式 (10) が成立することを確かめる．その ために, $5.9[\mathrm{~N}]$ の積載物を 2 等分して図 9 の (1)(2)に 示すような位㯰に置いた場合と， $5.9[\mathrm{~N}]$ の樌载物を 3
等分して図 9 の(3)〜(6)に示すような位膡に直いた場 合の 6 通りについて実験を行った，その結果得られた $\varepsilon_{F}$ および $\varepsilon_{R}$ を式(10)に代入して計算した $Q$ の值をブ ロットし, さらに, 樌載荷重の総量 5.9[N] の実線を記 入したものが図 10 である、いずれの場合も5.9[N] と 測定できることが確かめられる.

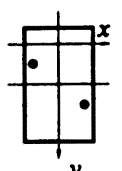

(1) $y$

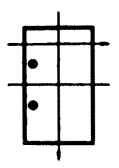

(2)

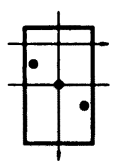

(3)

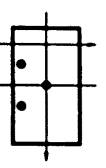

(4)

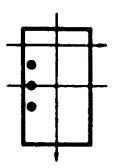

(5)

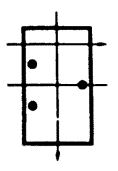

(6)

$\left(x_{p}, y_{p}\right) \quad\left(x_{p}, y_{p}\right)$

$\begin{array}{llll}(0,125) & (0,125) \quad(-80,125) \quad(80,125)\end{array}$

$(80,63) \quad(-80,63) \quad(-80,63) \quad(-80,63)$

Fig.9 Patterns of the load distribution

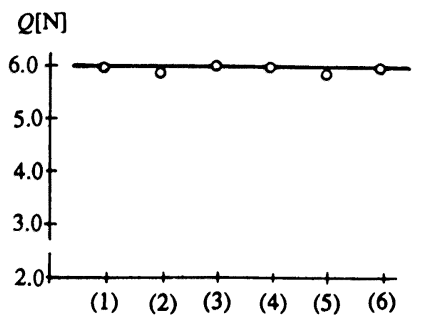

Fig.10 $Q$ by the patterns showed in Fig.9

$$
\text { 4.おわりに }
$$

货物自功車の前後車軸の中央から歪を検出すれば荷 台に䅡载された货物の重量を測定できるということを 述へた。しかしながら，荷台に相当させた鋼板の剛性 を一層低下させた場合についても上記のことが成立す るかどうか検刢の余地が十分残されている.さらに実 車に適用した場合についての検討も必須であり，また，

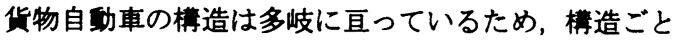
の対応が必要となるものと思われる.

\section{文献}

（1）佐藤武 監修,トラックー自動車工学全害 14 バスの車 体楼造, 山海堂, (1996)

（2）齐藤猛 監修，自動車用語中辞典，山海堂,(1992)

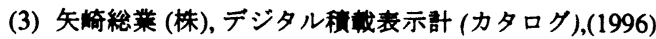

（4）千野，石坂，货物自動車の程覀重量を测定する一方法に

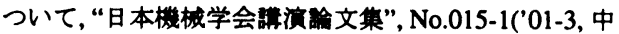
国四国支部 第 39 期総会・請演会), pp.281-282 